\title{
Design of Supervisory Control for Speed Control of Wind Turbine using Torque-Control Method Based on Buck Converter
}

\author{
Katherin Indriawati ${ }^{1, *}$, Choirul Mufit ${ }^{1}$, and Andi Rahmadiansah ${ }^{2}$ \\ ${ }^{1}$ Departement of Engineering Physics, Institut Teknologi Sepuluh Nopember, Jl. Teknik Kimia, \\ Surabaya 60111, East Java, Indonesia \\ ${ }^{2}$ Department of Electrical Engineering, National Taiwan University of Science and Technology, \\ Da'an District, Taipei City, 106 Taiwan
}

\begin{abstract}
The variation of wind speed causes the electric power generated by the turbine also varies. To obtain maximum power, the rotor speed of wind turbines must be optimally rated. The rotor speed can be controlled by manipulating the torque from the generator; this method is called Torque Control. In that case, a DC-DC converter is needed as the control actuator. In this study, a buck converter-based supervisory control design was performed on the Horizontal-axis wind turbines (HAWT). Supervisory control is composed of two control loops arranged in cascade, and there is a formula algorithm as the supervisory level. The primary loop uses proportional control mode with a proportional gain of 0.3 , whereas in the secondary loop using proportional-integral control mode with a proportional gain of 5.2 and an integral gain of 0.1 . The Supervisory control has been implemented successfully and resulted in an average increase in turbine power of $4.1 \%$ at $5 \mathrm{~m} \mathrm{~s}^{-1}$ and $10.58 \%$ at $6 \mathrm{~m} \mathrm{~s}^{-1}$ and $11.65 \%$ at $7 \mathrm{~m} \mathrm{~s}^{-1}$, compared to wind turbine systems without speed control.
\end{abstract}

Keywords: Cascade control, dc-dc converter, optimization of a wind turbine, torque control.

\section{Introduction}

The increase in population growth in Indonesia from year to year has an impact on the increasing consumption of electricity every year. In 2015, the amount of electricity produced by PLN sold to consumers increased by $2.14 \%$. In the same year the PLN statistics stated that there was an increase in the number of consumers by $6.39 \%$ or by 61167980 customers as of the end of 2015 compared to the end of 2014 [1]. Since most of the raw materials for electricity production in Indonesia still depend on fossil energy, the use of fossil energy in line with the increase in electricity consumption is also increasing. Based on data from the Agency for the Assessment and Application of Technology (BPPT), petroleum reserves have continued to decline from $5.9 \times 10^{9}$ in 1995 to $3.7 \times 10^{9}$ barrels at

\footnotetext{
*Corresponding author: katherin@ep.its.ac.id
} 
the end of 2015 and are predicted to run out within $11 \mathrm{yr}$. Besides coal resources over the last $4 \mathrm{yr}$ also decreased and are predicted to run out within $70 \mathrm{yr}$ if no new reserves are found [2]. With this condition, it has been suggested that people start switching to alternative energy sources, namely renewable energy.

Wind power or wind energy is one of the new renewable energies that can be developed in tropical countries such as Indonesia. The potential of wind energy in Indonesia is $950 \mathrm{MW}$ with wind speeds ranging from $2.5 \mathrm{~m} \mathrm{~s}^{-1}$ to $5 \mathrm{~m} \mathrm{~s}^{-1}$ [3]. Even LAPAN mentioned there are areas with wind speeds of more than $5 \mathrm{~m} \mathrm{~s}^{-1}$, namely NTT, NTB, South Sulawesi, and the South Coast of Java. With this great potential, Indonesia plans in 2005 to 2025 to succeed in utilizing wind power, reaching $5 \mathrm{MW}$ for on-grid, and $250 \mathrm{MW}$ for off-grid. However, in reality, the utilization of wind energy is still very lacking, evidently, only around $5.38 \%$ or only about $0.5 \mathrm{GW}$ of $950 \mathrm{MW}$ of the potential that Indonesia has [2].

However, in a wind power generation system, the proportion of available wind power converted to the mechanical power of the turbine is largely dependent on the blade-tip speed to the wind speed ratio of the turbine [3]. Consequently, the power generated is a nonlinear function of the turbine angular speed and the wind speed for a fixed blade pitch angle. With significant and abrupt variations in wind speed, it is, therefore, necessary to extract maximum power from the wind under normal operating conditions. One factor is the stochastic nature of wind energy. Stochastic nature in the form of fluctuating wind speeds causes the extraction of power generated by wind turbines is not optimal. To cope with changes in power production caused by the stochastic nature of wind energy, it is necessary to add control of the wind turbine to be able to maximize the electric power generated $[4,5]$.

Variable speed wind turbine (VSWT) is an effort to increase wind turbine power extraction by using direct torque control (DTC). In DTC, power optimization is done through optimal rotor torque tracking [5-7]. In implementing DTC, actuators are needed in the form of DC-DC converter or known as DC chopper in permanent magnet synchronous generators (PMSG) whose role is to keep the current or voltage generated by PMSG in its optimal area [8]. Buck converter is one type of DC-DC converter that serves to reduce the voltage or current output of the PMSG so that it is always at a set point that has been set [9]. In implementing DC-DC converter, a controller is needed to provide the control strategy that must be carried out by the converter. Some controllers that are often used include maximum power point tracking (MPPT), supervisory control, and fuzzy logic predictive controller [10].

The use of DC-DC converter in VSWT will be more maximal if using supervisory control compared to using MPPT [6]. Therefore, in this study, the supervisory control was implemented on variable speed wind turbines (VSWT) using a buck converter-based torque control. The algorithm used for the setpoint adjustment in supervisory control is the reference formula.

\section{Research methods}

The steps that have been taken in this study are as follows:

\subsection{Sensor design and testing}

The voltage sensor used is a voltage divider. The voltage divider functions to measure the output voltage of the buck converter as an input to the load circuit. The resistor values applied to the system are obtained using Equation (1). As for current and voltage sensors, INA219 sensor module is installed at the output rectifier or input of the buck converter. The INA219 sensor module is as shown in Figure 1. 


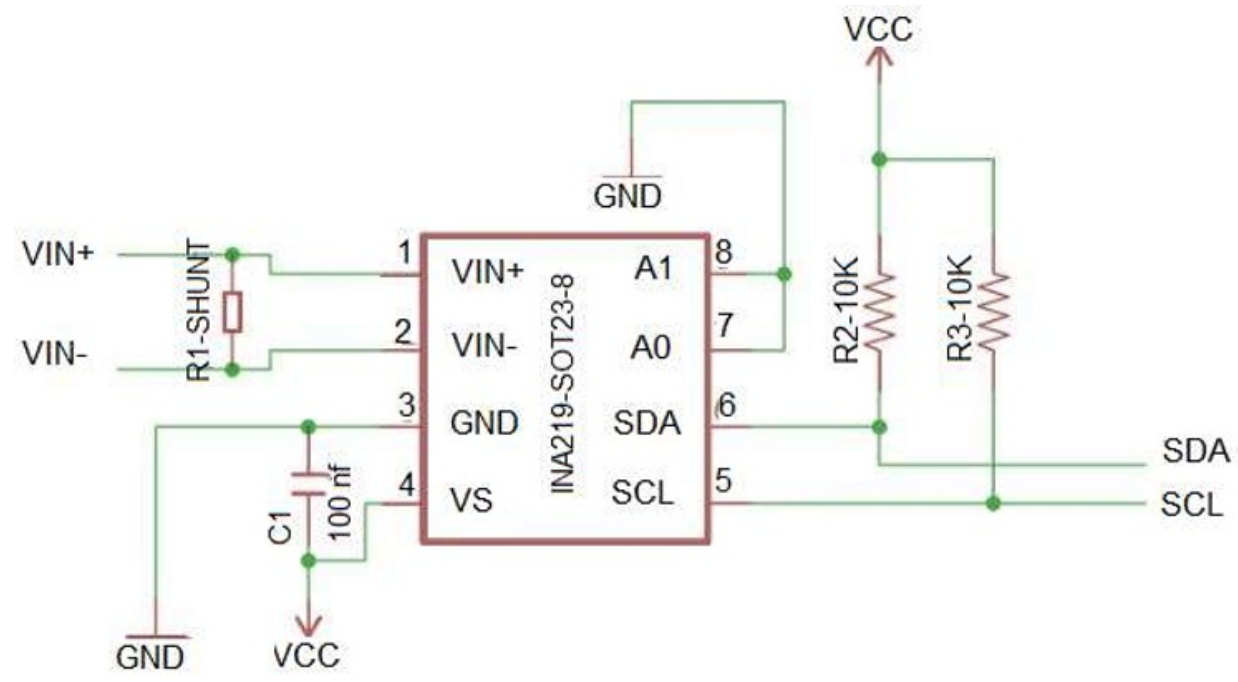

Fig 1. Sensor ina219 circuit module.

$$
V o=\frac{R_{1}}{R_{1}+R_{2}} \times V i
$$

By using the $\mathrm{I} 2 \mathrm{C}$ communication protocol, the sensor can be more easily connected with only two cable lines. The SCL and SDA pins are connected to A4 (SCL), and A5 (SDA) pins on Arduino. Each lane is added with a resistor of $10 \mathrm{~K}$ as a pull-up resistor that functions so that when there is no current to flow, the sensor output is high per $5 \mathrm{~V}$. VCC and GND pins are connected to the Arduino 5V pin and GND. The INA219 sensor basically has the same concept as other DC sensors, but this sensor not only measures current but also measures voltage so that the power value can be measured using this sensor.

\subsection{Design and implementation of buck converter}

The DC-DC converter implemented in this study is a buck converter. The buck converter is installed to control the current at the PMSG generator that previously passed the rectifier. The buck converter circuit is shown in Figure 2.

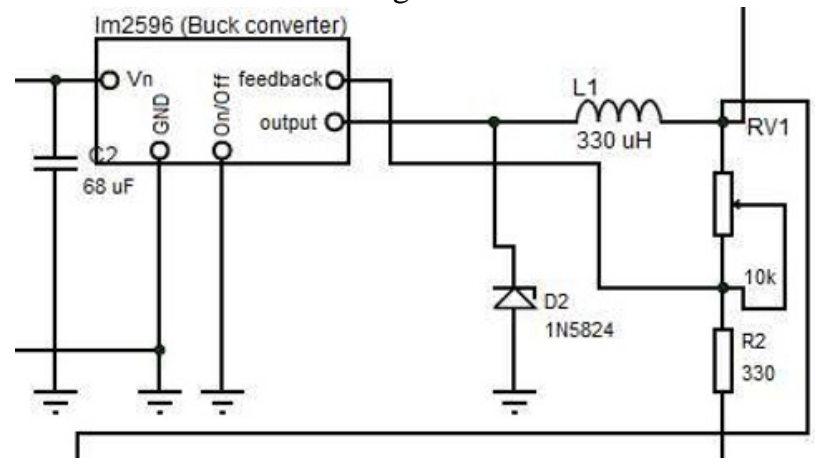

Fig. 2. Buck converter circuit. 
The component of buck converter used is referring to the values contained in the reference circuit, as shown in Figure 2. The converter component values other than IC switching are shown in Table 1.

Table 1. Buck converter component value.

\begin{tabular}{|c|c|c|}
\hline No & Parameter & Value \\
\hline 1 & Resistor & $330 \Omega$ \\
\hline 2 & Inductor & $330 \mathrm{uH}$ \\
\hline 3 & Capacitor & $68 \mathrm{uF}$ \\
\hline
\end{tabular}

Buck converter voltage drop is generally controlled by adjusting MOSFET switch based on the duty cycle of the PWM signal. PWM used is PWM with a resolution of 10 bits, which means that the PWM has a variety of changes in the value of 210 or 1024 in which the value represents the duty cycle value of $0 \%$ to $100 \%$.

\subsection{Design and implementation of load circuits}

Manipulation of the voltage that enters the load using a buck converter will cause the current generated to be manipulated. Therefore, after conducting several experiments on the turbine loading, namely resistive load ( $22 \Omega, 5 \mathrm{~W}$ ), inductive loads (DC motors $5.9 \mathrm{~V}$ ), and capacitive loads (lithium batteries 3.7.7 V, $2200 \mathrm{mAh}$ ). Then, a total of four batteries are selected, arranged in parallel series so as to produce a value of total battery of $5 \mathrm{~V}, 8$ $000 \mathrm{mAH}$ with the consideration of testing the value of the current on all three loads as listed in Table 2.

Table 2. Current comparison of several loads.

\begin{tabular}{|c|c|c|c|c|}
\hline No & Parameter & Resitive & Inductive & Capacitive \\
\hline 1 & Wind Speed $\left(\mathrm{m} \mathrm{s}^{-1}\right)$ & 6 & 6 & 6 \\
\hline 2 & Current Value $(\mathrm{mA})$ & 120 & 56 & 132 \\
\hline
\end{tabular}

The load position in the system can be seen in Figure 3.

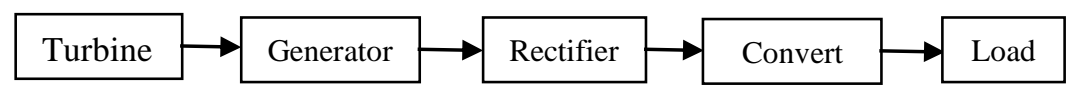

Fig 3. The overall system arrangement.

The torque control method in the system is torque control by controlling the current in the generator. Therefore, a loading effect is given to the turbine system so that the load torque arises towards the load. If the current is high, the rotor will produce lower speed because the load torque is high and vice versa. If the current is low, and the load torque is high, it results in higher rotor speed. Thus, the control method can be done by manipulating the load voltage using a buck converter.

\subsection{Design of cascade control and supervisory level}

The design begins with a cascade controller which is composed of current control on the inner loop and rotor speed control on the outer loop. The design of the cascade controller is done on the inner loop, and then continues on the outer loop. In determining the $\mathrm{Kp}$ and $\mathrm{Ki}$ gain values, the tuning method used uses trial \& error method to produce a response with a 
steady state error of $\pm 5 \%$. From the resulting tuning, the parameter values for each controller are obtained as follows:

i. Kp Inner Loop (secondary loop) $=5.2$

ii. Ki Inner Loop (secondary loop $=0.1$

iii. Kp Outer Loop (primary loop) $=0.3$

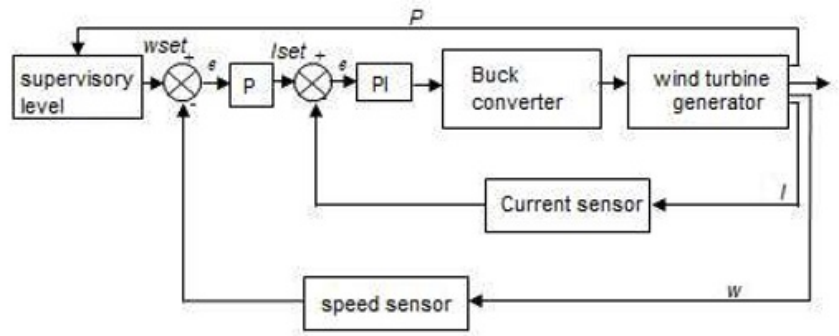

Fig 4. Block diagram of supervisory control.

After rotor speed control is set as the set point of the outer loop, the reference formula is used as an algorithm to find the optimal speed value. This algorithm is composed of several equations that use units of PU (Per Unit). The Equation is a turbine equation that is generally accepted in which we have to determine the $\mathrm{P}$ nominal value to change the measured power unit into a unit as contained in Equation (2):

$$
P u=\frac{P_{\text {measure }}}{P_{\text {nominal }}}
$$

The value of PU (unit power) is then entered into Equation (3) to obtain the $₫$ ref value from the reference formula Equation (3).

$$
\omega_{r e f}=\left(-0.67 \times P u^{2}\right)+(1.42 \times P u)+0.5
$$

The value of oref is then multiplied by onominal to get the value of øset as contained in the Equation (4):

$$
\omega_{\text {set }}=\omega_{\text {ref }} \times \omega_{\text {nominal }}
$$

As for the calculation and search of the P nominal and $\omega$ nominal values in order to obtain the optimum set point at various speeds is done by trial error and calculation. After several attempts of combination of $\mathrm{P}$ nominal and $\Phi$ nominal, the value of $\omega$ nominal $=667.80 \mathrm{rpm}(1 \mathrm{rpm}=1 / 60 \mathrm{~Hz})$ and $\mathrm{P}$ nominal $=17.6 \mathrm{~W}$ are obtained. In which the $\Phi$ nominal value meets the $\omega$ value for the wind turbine system at a speed of $7 \mathrm{~m} \mathrm{~s}^{-1}$ in the open loop state.

\section{Results and discussion}

The results and discussion that have been carried out in this study are as follows:

\subsection{Sensor testing results}

Sensor calibration aims to determine the uncertainty value of the measurement results. Calibration is performed on the voltage sensor and current sensor. Intake is done by comparing the measurement results from the sensor then compared with the measurement 
results on a standard device (Multimeter). Based on the several uncertainty calculations, until the extended uncertainty is obtained, the resulting uncertainty for the voltage sensor is \pm 0.601864 and the current sensor is 0.608381 with a $95 \%$ confidence level from the $\mathrm{T}$-Student table. The uncertainty will be a reference for reading as long as the instrument is used.

\subsection{Loading effect results}

The response of the wind turbine rotor speed and current on the load is as shown in Figure 5 and Figure 6.

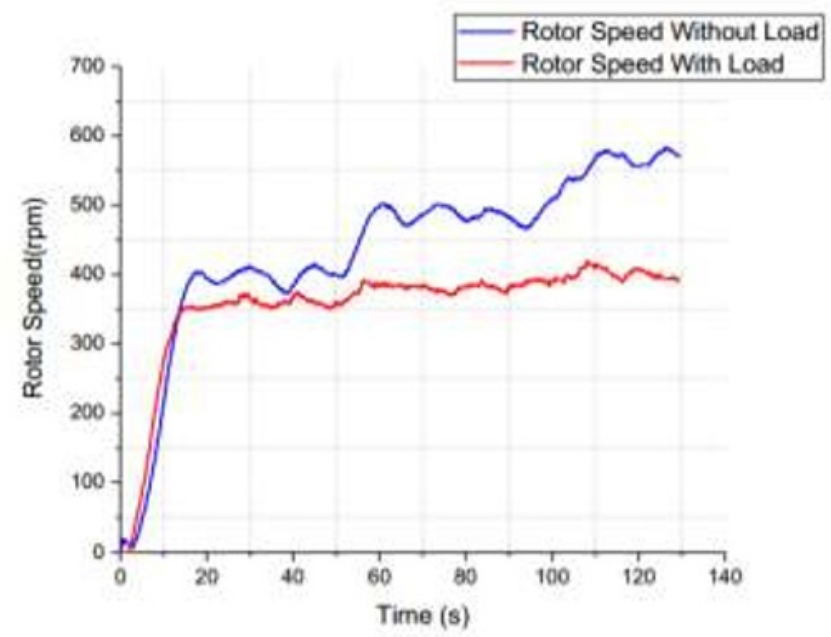

Fig 5. Response of rotor speeds at different speeds.

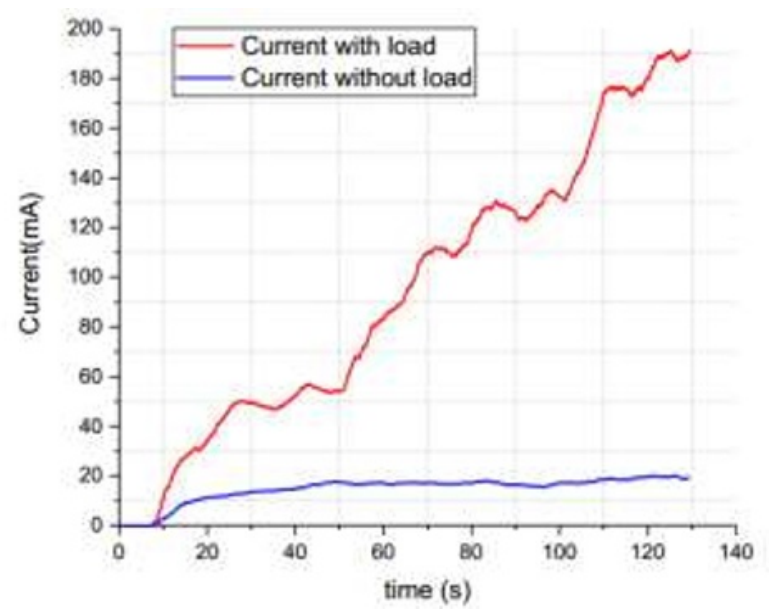

Fig 6. Response of generator output currents at different speeds.

From Figures 5 and Figure 6 it can be seen that the loading effect on the turbine system results in differences in the value of the velocity measurement. The blue line is the speed of the rotor when the turbine system is not given a load so that the wind turbine system runs in 
an open circuit with low torque and low current but with a maximum turbine rotor speed. While the red line is the speed of the rotor when the turbine system is connected to the load, in which the torque and the currents are high but with lower turbine rotor speed. In this test, no control action has been taken so that the power generated is not optimum.

\subsection{Buck converter test results}

The buck converter that has been made is tested by giving a variation of the PWM value. The PWM value previously explained in the previous section, will affect the voltage drop in the buck converter. This decrease occurs because the IC switches in the circuit open and closes along with the width and frequency given by the gate IC. This pulse width can be changed by coding on arduino. Thus the buck converter output voltage value can be changed by changing the value of the pulse width (PWM) as shown in Figure 7. The data is taken on the condition of the circuit is not connected to the load with a speed of $6 \mathrm{~m} \mathrm{~s}^{-1}$.

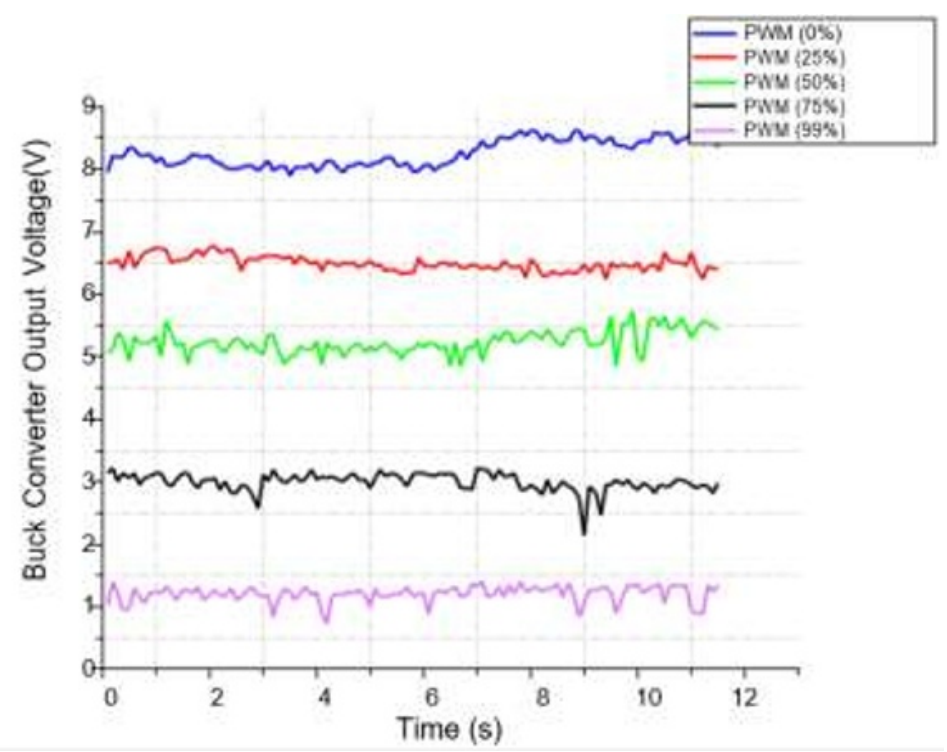

Fig 7. Response of buck converter output voltage to the increasing of PWM value.

Manipulation of the voltage flowing on the load will affect the loading effect. The higher the voltage on the load, the higher the current flowing and torque, it results in lower turbine rotor speed. And vice versa, the lower the voltage on the load, the lower the current flowing and torque, it results in higher turbine rotor speed. The PWM relationship to current and speed is shown in Figures 8 and Figure 9. 


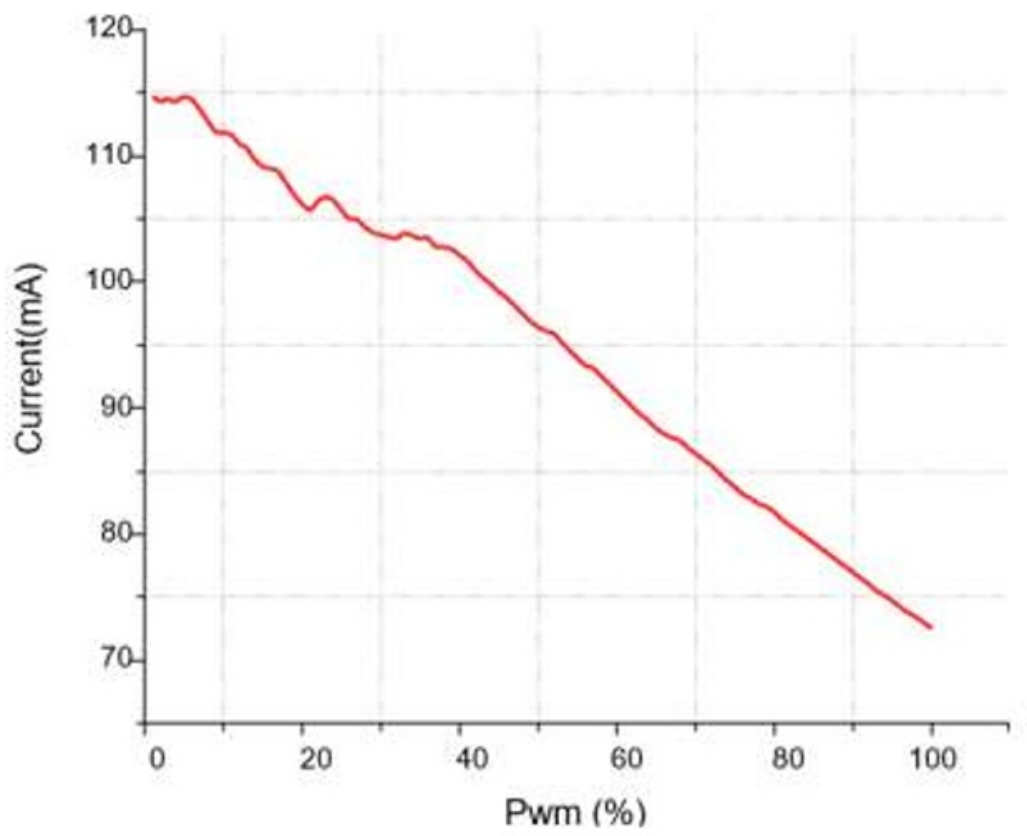

Fig 8. Relation between the increasing of PWM value and the generator current.

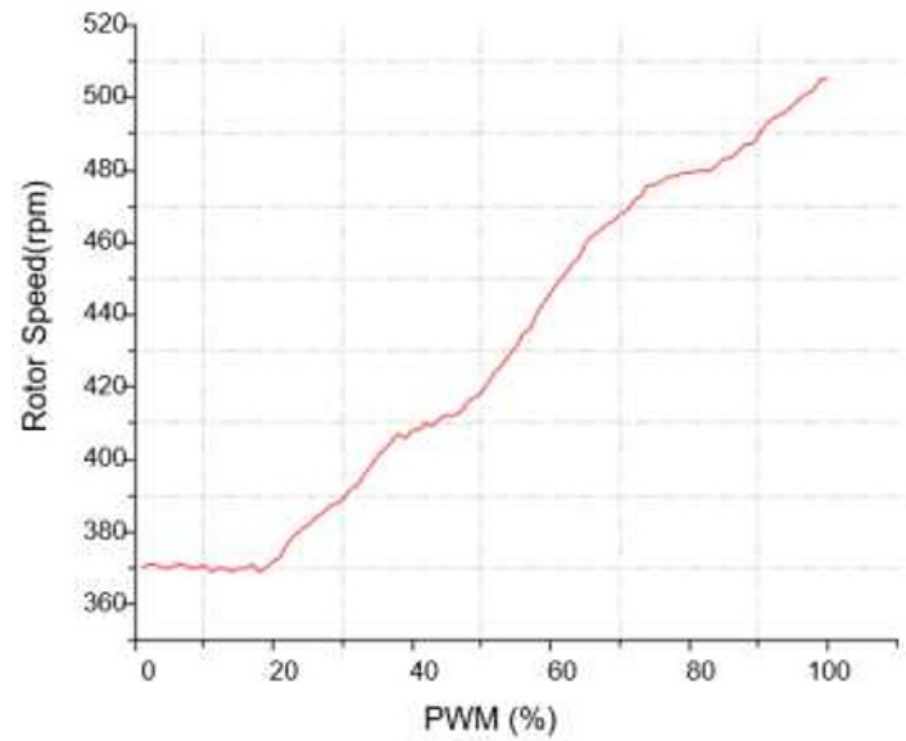

Fig 8. Relation between the increasing of PWM value and the turbine rotor speed. 


\subsection{Current control results (inner loop)}

The current control system is made by manipulating the PWM given to the buck converter. The results of the current tracking response are as in Figure 10 while the speed response is in Figure 11.

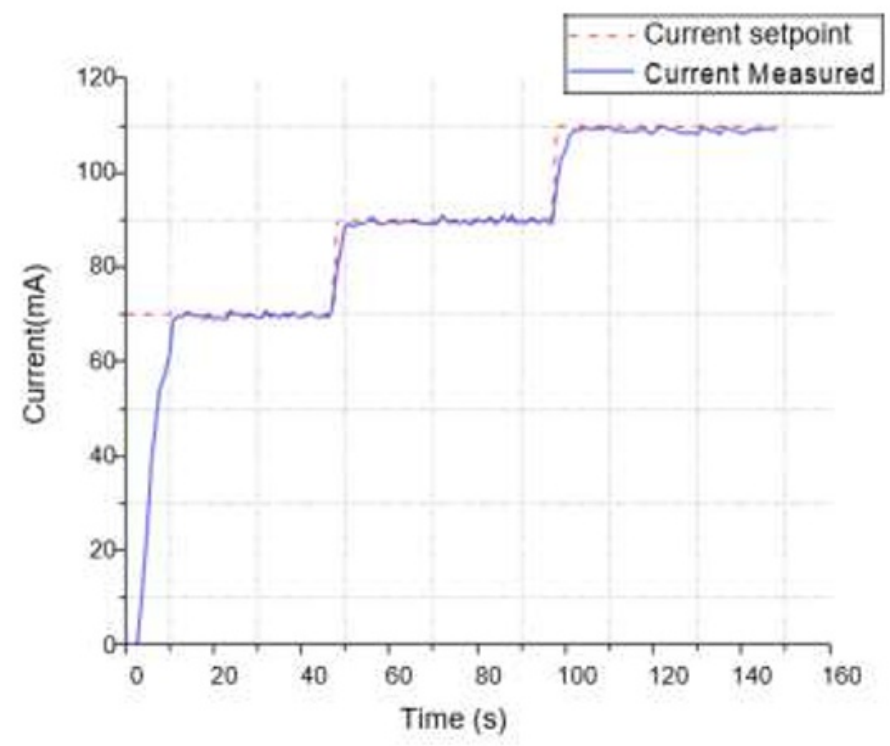

Fig 10. Response of the current tracking at several set point.

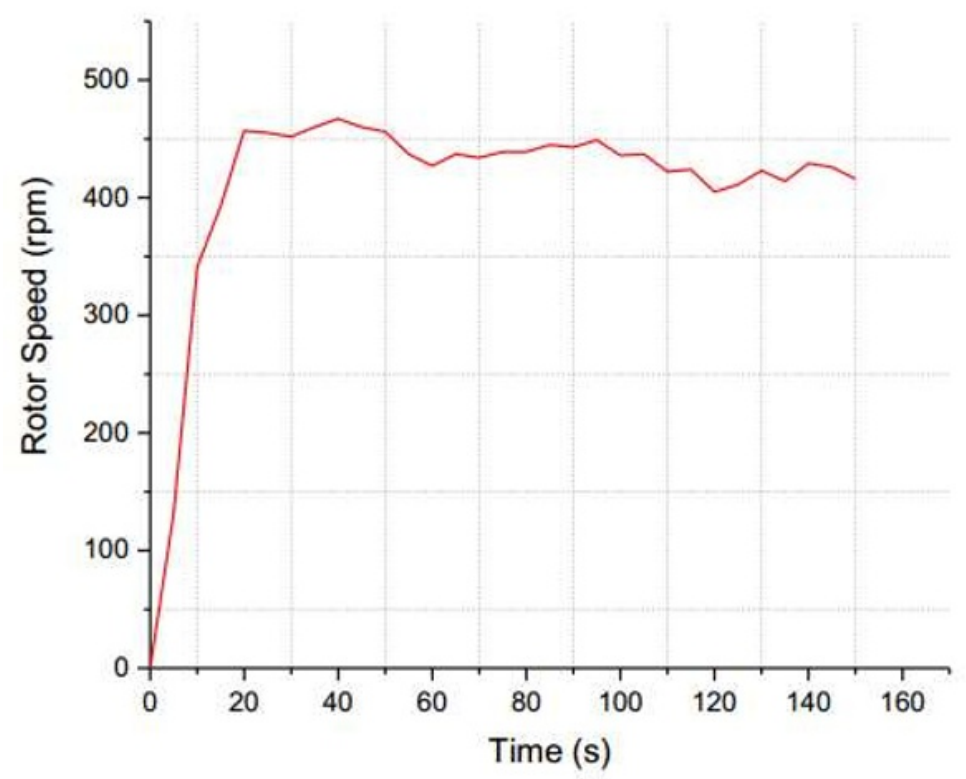

Fig 11. Response of speed to the current tracking. 
The responses in Figure 10 and Figure 11 are obtained at wind speeds of $6 \mathrm{~m} \mathrm{~s}^{-1}$ with a voltage of $4 \mathrm{~V}$ under load condition. The method used is PI control where the tuning is done using trial and error methods with a $\mathrm{Kp}$ value of 5.2 and $\mathrm{Ki}$ of 0.1 . The system response specifications are as follows:

Table 3. Current Control System Specification Response

\begin{tabular}{|c|c|}
\hline System response specification & Value \\
\hline Peak time (s) & 13.5 \\
\hline Rise time (s) & 7.5 \\
\hline Maksimum overshoot (\%) & 2.6 \\
\hline Setling time (s) & 11 \\
\hline
\end{tabular}

The results of the flow control response based on system responses in Table 3 are as designed. The response of the turbine rotor speed is getting lower as shown in Figure 11 due to the three set point currents. The value is getting higher, set point 1 is $70 \mathrm{~mA}$, set point 2 is $90 \mathrm{~mA}$ and set point 3 is $110 \mathrm{~mA}$. After testing the current tracking produces a good system response, speed tracking is done by determining several speed set points and manipulating the current so that the speed is at the set point. The speed tracking test will be discussed in the next section.

\subsection{Speed control results (outer loop)}

The speed control system is made by manipulating the current set point. The speed tracking response results are shown in Figure 12.

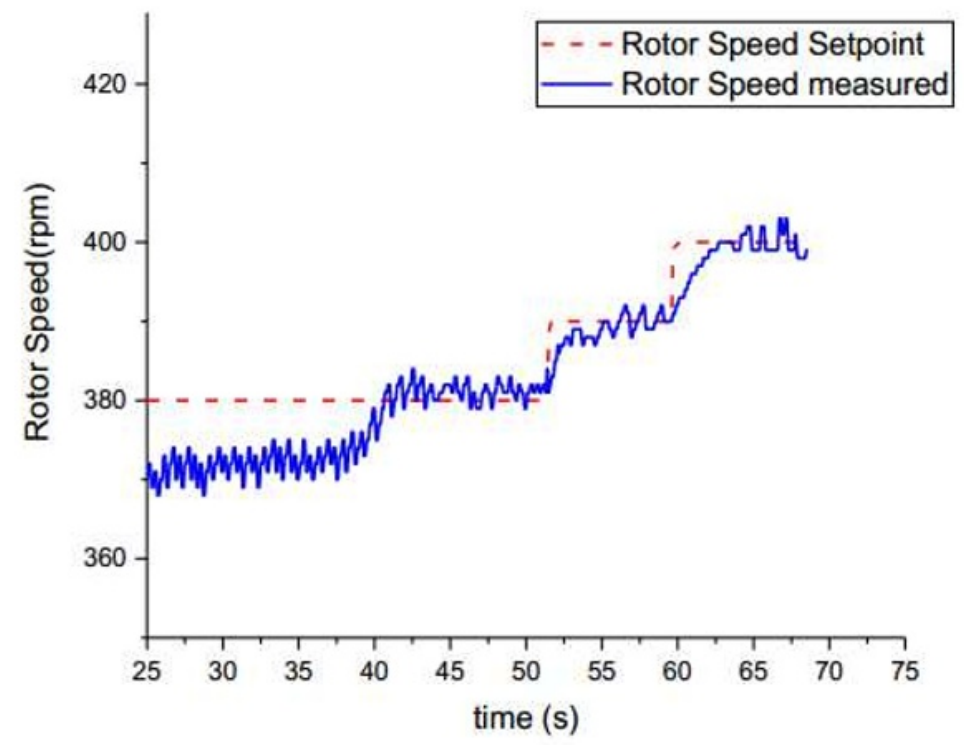

Fig 12. Speed tracking responses at several set points.

The response above is obtained at a wind speed of $6 \mathrm{~m} \mathrm{~s}^{-1}$, the method uses P control in which the tuning is done using trial and error methods with a $\mathrm{Kp}$ value of 0.3 . The system response specifications are in Table 4. The results of the speed control response 
based on the system responses in Table 4 are as designed. The response takes a longer time because the speed control is the outer loop in the system. It can also be seen from Figure 12 that the control system can maintain the measured value in the region of steady state error so that it can be said that the speed control works quite well.

Table 4. Speed Control System Specification Response

\begin{tabular}{|c|c|}
\hline System response specification & Value \\
\hline Peak time (s) & 41 \\
\hline Rise time (s) & 14.85 \\
\hline Maksimum overshoot (\%) & 1.5 \\
\hline Setling time (s) & 37 \\
\hline
\end{tabular}

\subsection{Implementation of supervisory control based on reference formula}

The final step is the overall implementation of supervisory control by adding supervisory levels based on the reference formula that has been made. The reference formula processes the measured power data and then divided by the nominal power as contained in the design. The result of this division is PU (Power unit), and then the value of this power goes into Equation (2) to Equation (4). Meanwhile tracking the response of the turbine rotor speed to the set point obtained from the reference formula carried out at changes in the speed of $5 \mathrm{~m} \mathrm{~s}^{-1}, 6 \mathrm{~m} \mathrm{~s}^{-1}$ and $7 \mathrm{~m} \mathrm{~s}^{-1}$ as shown in Figure 13.

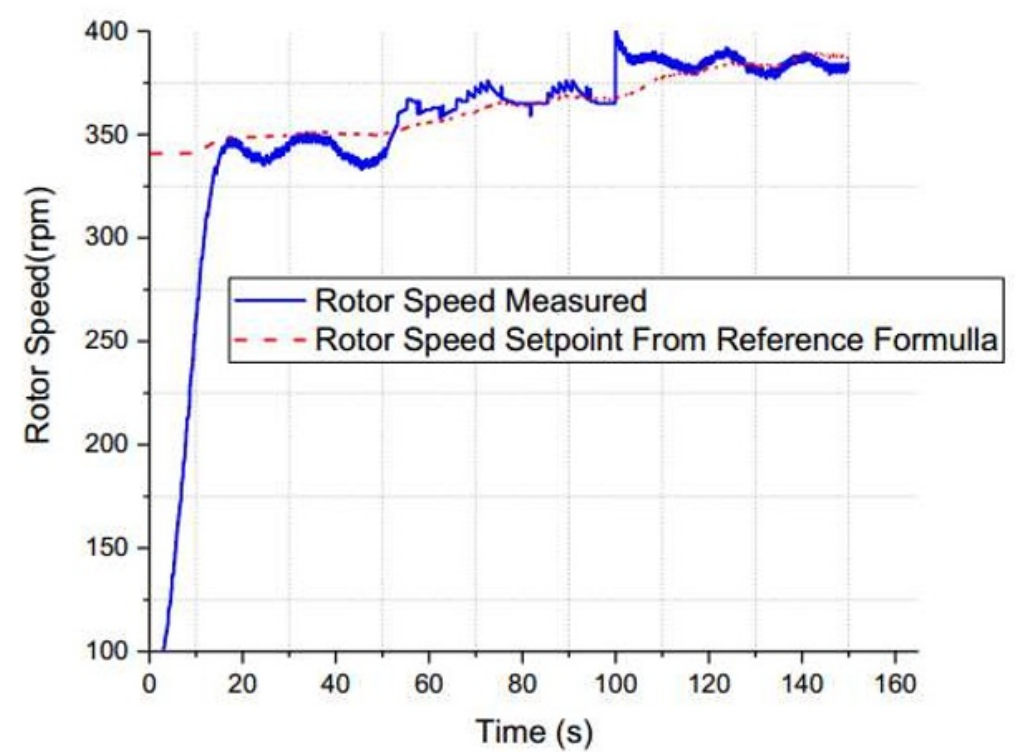

Fig 13. Response of speed tracking to the set point generated by the reference formula.

The system response specifications listed in Table 5 are several parameters such as settling time, rise time, peak time, and maximum overshoot. 
Table 5 Speed Control System Specification Response with reference formulla

\begin{tabular}{|c|c|}
\hline System response specification & Value \\
\hline Peak time (s) & 19 \\
\hline Rise time (s) & 17 \\
\hline Maksimum overshoot (\%) & 2.35 \\
\hline Setling time (s) & 31.5 \\
\hline
\end{tabular}

Based on Figure 13, it is known that the supervisory control can be applied with the system response as seen in Table 5. Overshoot speeds occur at $50 \mathrm{~s}$ and $100 \mathrm{~s}$ in the response. This is because at $50 \mathrm{~s}$ the wind speed is changed from $5 \mathrm{~m} \mathrm{~s}^{-1}$ to $6 \mathrm{~m} \mathrm{~s}^{-1}$ and at $100 \mathrm{~s}$ the wind speed is changed from $6 \mathrm{~m} \mathrm{~s}^{-1}$ to $7 \mathrm{~m} \mathrm{~s}^{-1}$. A few seconds later, along with the increase in set point given by the reference formula, the measured speed also drops towards the tracking set point.

\subsection{Comparison of turbine power using supervisory control to turbine power without speed control}

Comparison is done by taking data from the turbine system with supervisory control compared to the turbine system without speed control. Without control, means that the buck converter is not turned on so that in the system, after the rectifier, it goes directly into the load without any voltage or current control. The comparison of power values with supervisory control and without speed control is shown in Figure 14.

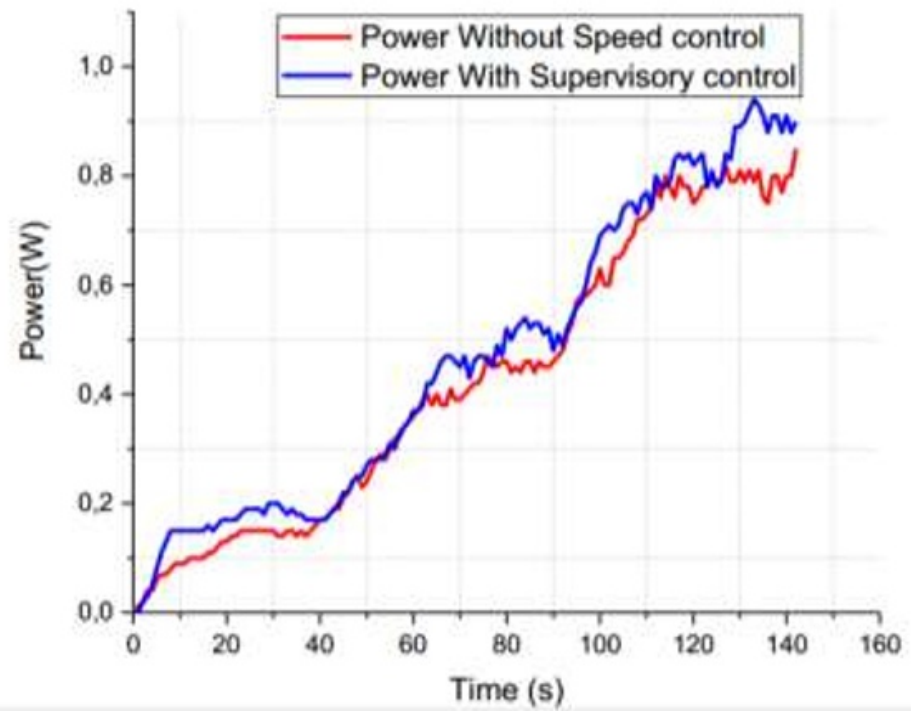

Fig 14. Comparison value of turbine power using supervisory control to turbine power without speed control.

From the graph above it can be seen that the increase in turbine power from supervisory control has been successfully implemented even though the difference is not so big. As for the speed of $5 \mathrm{~m} \mathrm{~s}^{-1}$, it is known that the average increase in power is $4.1 \%$ with the acquisition of power increasing from $0.166 \mathrm{~W}$ to $0.172 \mathrm{~W}$, the speed of $6 \mathrm{~m} \mathrm{~s}^{-1}$ with an average increase of $10.57 \%$ with the acquisition of power from $0.45 \mathrm{~W}$ to $0.50 \mathrm{~W}$, and a 
speed of $7 \mathrm{~m} \mathrm{~s}^{-1}$ with an average increase of $11.65 \%$ with the acquisition of power from $0.80 \mathrm{~W}$ to $0.90 \mathrm{~W}$.

\section{Conclusion}

From the results of the study, there are several points that can be concluded regarding the supervisory control that has been made. Buck converter-based supervisory control is able to control turbine speed with controller performance with steady state error values of less than $5 \%$, peak time of $19 \mathrm{~s}$, rise time of $17 \mathrm{~s}$, settling time of $31.5 \mathrm{~s}$ and maximum overshoot of 2.35. The Supervisory control has been implemented successfully and resulted in an average increase in turbine power of $4.1 \%$ at wind speed of $5 \mathrm{~m} \mathrm{~s}^{-1}$ and $10.58 \%$ at wind speed of $6 \mathrm{~m} \mathrm{~s}^{-1}$ and $11.65 \%$ at wind speed of $7 \mathrm{~m} \mathrm{~s}^{-1}$, compared to the wind turbine systems without speed control.

\section{References}

1. Corporate Secretary PT PLN. PLN statistic 2015. Jakarta: PT PLN (Persero) (2016). p. 104. https://web.pln.co.id/statics/uploads/2017/06/Statistik-PLN-2015English.pdf

2. Secretariat General of National Energy Council. Indonesia Energy Outlook 2016. Jakarta: Secretariat General of National Energy (2016). p. 61. https://www.esdm.go.id/assets/media/content/content-indonesia-energyoutlook-2016-versi-inggris-my33nxb.pdf

3. R.B. Gavino, J.C.Y. Ng, R.L. Ng, B.L. Tan, A.Y. Chua, DLSU Engineering eJournal, 1,1:28-42(2007)

http://www.dlsu.edu.ph/wpcontent/uploads/pdf/research/journals/dlsuengj/pdf/vol1no1/03.pdf

4. Y. Yuan, J. Tang, Engineering 3,4:494-503(2017). https://www.sciencedirect.com/science/article/pii/S2095809917306094

5. A. Kusiak, H. Zheng, Energy, 35, 1:1324-1332(2010). https://www.sciencedirect.com/science/article/abs/pii/S0360544209004897

6. T. Armaditya, H. Suryoatmojo, T. Yuwono, Jurnal Teknik POMITS 1, 1:16(2010). [in Bahasa Indonesia] http://digilib.its.ac.id/public/ITS-paper-229782210105019-Paper.pdf

7. B. Pratap, N. Singh, V. Kumar, Robust control of variable speed wind turbine using quai sliding mode approach. Paper presented in 6th International Conference on Smart Computing and Communication, (Kurukshetra, India, 2017). http://www.ijicic.org/ijicic-11-08026.pdf

8. C. Elmas, O. Deperlioglu, H.H. Sayan, Expert. Syst. Appl. 36,1:15401548(2009).

https://www.sciencedirect.com/science/article/abs/pii/S0957417407006021

9. M. Firad, S. Nababan, Evaluasi topologi konverter DC-DC untuk memperbaiki kinerja pembangkit listrik tenaga angin pengisi batere. [Evaluate the topology of DC-DC converters to improve the performance of battery chargers] [Thesis] Department of Electrical Engineering, Engineering Faculty, University of Mataram, (2007). p. 35. [in Bahasa Indonesia] 
http://perpustakaan.bappenas.go.id//ontar/file?file=digital/92254-[_Konten_]MUHAMMAD\%20FIRAD,\%20ST;\%20SABAR\%20NABABAN,\%20ST.,\%20 MT.pdf

10. Ummah, A. Milatul (2018) Supervisory control untuk pengendalian kecepatan turbin angin. [Supervisory control for controlling wind turbine speed] [Undergraduate thesis] Department of Physic Engineering, Faculty of Industrial Technology, Institut Teknologi Sepuluh Nopember, (2018). [in Bahasa Indonesia]. http://repository.its.ac.id/50921/ 